\title{
Preparation and characterization of palladium ceramic alumina membrane for hydrogen permeation.
}

ORAKWE, I., SHEHU, H. and GOBINA, E.

2019 


\title{
PREPARATION AND CHARACTERIZATION OF PALLADIUM CERAMIC ALUMINA MEMBRANE FOR HYDROGEN PERMEATION
}

\author{
Ifeyinwa Orakwe, Habiba Shehu and Edward Gobina* \\ Robert Gordon University, School of Engineering, Center for Process Integration and Membrane Technology, Aberdeen, \\ United Kingdom \\ *Corresponding author e-mail: e.gobina@rgu.ac.uk
}

\begin{abstract}
In this study, a tubular palladium membrane has been prepared by an electroless plating method using palladium II chloride as a precursor with the intent of not having a completely dense film since its application does not require high hydrogen selectivity. The support used was a $15 \mathrm{~nm}$ pore sized tubular ceramic alumina material that comprise of $77 \%$ alumina and $33 \%$ titania. It has dimensions of $7 \mathrm{~mm}$ inner and $10 \mathrm{~mm}$ outer diameters respectively. The catalyst was deposited on the outside tube surface using the electroless deposition process. The membrane was morphologically characterized using scanning electron microscopy/energy dispersive $x$-ray analysis (SEM/EDXA) and liquid nitrogen adsorption/desorption analysis (BET) to study the shape and nature of the palladium plating on the membrane. The catalytic membrane was then inserted into a tubular stainless-steel holder which was wrapped in heating tapes so as to enable the heating of the membrane in the reactor. The gases used for permeation tests comprised $\mathrm{H}_{2}, \mathrm{~N}_{2}, \mathrm{O}_{2}$ and $\mathrm{He}$. Permeation tests were out at $573 \mathrm{~K}$ and at pressure range between $0.05-1 \mathrm{barg}$. The results showed that hydrogen displayed a higher permeation when compared to other gases that permeated through the membrane and its diffusion is also thought to include solution diffusion through the dense portions of the palladium in addition to Knudsen, convective and molecular sieving mechanisms occurring through cracks and voids along the grain boundaries. While high hydrogen selectivity is critically important in connection with hydrogen purification for fuel cells and in catalytic membrane reactors used to increase the yield of thermodynamically limited reactions such as methane steam reforming and water-gas shift reactions whereby the effective and selective removal of the $\mathrm{H}_{2}$ produced from the reaction zone shifts the equilibrium, it is not so important in situations in which the membrane has catalytic activity such that it is possible to carryout the reaction in situations where the premixed reactants are forced-through the membrane on which the catalysts is attached. This type of catalytically active membranes is novel and has not been tested in gassolid-liquid reactions and liquid-solid reactions before. With such a reactor configuration, it is possible to achieve good feed stream distribution and an optimal usage of the catalytic material. The preparation and characterization of such membrane catalysts has gained increased interests in the process industries because it can be adapted to carryout the chemical reactions if one of the reactants is present in low concentration and an optimal reactant distribution results in a better utilization of the active catalytic material. However, there are concerns in terms of the high cost of palladium membranes and research on how to fabricate membranes with a very low content of the palladium catalyst is still ongoing. Work is currently underway to deploy the $\mathrm{Pd} / \mathrm{Al}_{2} \mathrm{O}_{3}$ membrane catalysts for the deoxygenating of water for downhole injection for pressure maintenance and in process applications.
\end{abstract}

KEYWORDS: Hydrogen, Ceramic Membrane, Palladium, Permeance, Electroless Plating, SEM/EDXA

\section{INTRODUCTION AND LITERATURE REVIEW}

The production of high-purity hydrogen for various industrial purposes has become of importance in recent times (Alique, Martinez-Diaz, Sanz and Colins 2018). Hydrogen, which at the point of use is an excellent alternative renewable energy, has drawn so much attention as a result of problems generated by $\mathrm{CO}_{2}$ emissions and global warming (Rahimpour et al. 2017). The use of inorganic membranes and in particular palladium coated membranes has shown great application in hydrogenation and dehydrogenation reactions (Kiliçarslan, Afyon and Doğan 2008) (Alique, Martinez-Diaz, Sanz and Colins 2018) (Li 2007) and this is so because these palladium membranes are seen to be highly stable and possess high selectivity towards hydrogen (Chen and Gobina 2013) (Collins and Way 1993) (Hamilton 2012).

There are various methods that can be used to prepare palladium alloyed membrane. Some examples are: electrolytic plating, electroless plating, chemical vapour deposition, magnetron sputtering, spray pyrolysis, anodic oxidation and sol gel techniques respectively (Kiliçarslan, Afyon and Doğan 2008) (Jiang, Goldbach, Bao, Yu and Xu 2008) (Li, Liang and Hughes 2000) (Checchetto, Bazzanella, Patton and Miotello, 2004). Lately the need for thin palladium-alloy films in preference to the thick free-standing dense metal membranes has been on the increase (Chen and Gobina 2013) (Exter 2014). 
For the purpose of this study, a tubular ceramic alumina support was selected. Alumina ceramic membranes are mostly chosen for membrane catalysts development because they possess some unique properties: its crystal compact structure allows for strong chemical bonds which are thermally and chemically stable and also its ability in creating a larger separation area per unit volume for the reaction process (Li, Liang and Hughes 1998). Studies have also shown that dense palladium metals are highly selective in the separation of hydrogen gas (Li et al. 2014) and hydrogen transport generally characterized by the solution diffusion transport model based on external mass transfer, surface adsorption and desorption, transition to and from the bulk palladium and diffusion within the palladium metal (Chen and Gobina 2010) (Kikuchi and Uemiya 1991).

The current work presents the preparation of a palladium alumina membrane, its characterization and experimental results on the permeance and selectivity of hydrogen over other gases. The pore size, specific surface area and pore size distribution were obtained using quantachrome analyzer and comparison were made between the palladium coated membrane and a fresh support. The palladium layer is deliberately not made completely dense as it is intended to be used as a flow-through catalytic membrane reactor in which the premixed reactants are directed to flow through and interact with the palladium catalyst layer in a single pass aiming to reach complete reactants conversion by taking advantage of the high catalytic activity and efficiency created due to the intensification of contact between the catalytic material and feed stream. In the wastewater treatment industry today, the supports used in this study to deposit the palladium layer are also already being used in removing contaminants in forced flow-through (cross flow) configuration and therefore the route to commercialization will not follow a very steep gradient learning curve (Fard et al. 2018).

\section{MATERIAL AND METHODS}

An ultra-thin palladium membrane was prepared by an electroless plating method adopted from Li (Li, Liang and Hughes 1998). The process involved three steps. The first two of which are sensitization and activation steps were carried out together and then the last step is the palladium plating itself.

\subsection{Membrane preparation}

The alumina support used was a 360mm long mesoporous alumina ceramic support tube purchased from Ceramiques Techniques et Industrielles (CTI SA, France) with an inner and outer diameter of 7 and $10 \mathrm{~mm}$ respectively and a pore size of $15 \mathrm{~nm}$. Its composition was made up of $77 \%$ alumina and $23 \% \mathrm{TiO}_{2}$. The support was initially dried for 2 hours at $338 \mathrm{~K}$ in an oven to remove moisture and weighed subsequently. This was then followed with the sensitization and activation step. The sensitization involved the support being dipped into a tin solution for 5 minutes; this is then followed by a 2 minutes rinse in deionized water and then dipped in a palladium solution for another 5 minutes. This process was repeated 10 times so as to achieve a uniformly palladium activated surface. The tin and palladium solutions were both of $0.005 \mathrm{M}$ concentration. After the sensitization and activation steps, the support was allowed to air dry at room temperature for 24 hours and subsequently in an oven at $338 \mathrm{~K}$ for up to 4 hours. Its weight was also recorded at this point. There was a $0.1 \mathrm{~g}$ increase in weight. The last step in the process is the plating step. Both ends of the support bore were covered with a Teflon tape to prevent the solution coming into contact with the inner surface of the support. The plating involved placing the activated support into an electroless plating bath as shown in Fig 1. The composition of the plating bath is also shown in Table 1 (Yeung, Christiansen and Varma 1999). The support was kept in the plating bath for 2 hours. The plated membrane was then dried in an oven at $338 \mathrm{~K}$ for 10 hours (Li, Liang and Hughes 1998).

Table 1 Plating solution composition

\begin{tabular}{|l|l|}
\hline $\mathrm{PdCl}_{2}$ & $2.7 \mathrm{~g}$ \\
\hline $\mathrm{NH}_{4} \mathrm{OH}$ & $440 \mathrm{ml}$ \\
\hline $\mathrm{Na}_{2}$ EDTA & $70 \mathrm{~g}$ \\
\hline $\mathrm{N}_{2} \mathrm{H}_{4}$ & $10 \mathrm{ml}$ \\
\hline Temperature & $333 \mathrm{~K}$ \\
\hline
\end{tabular}




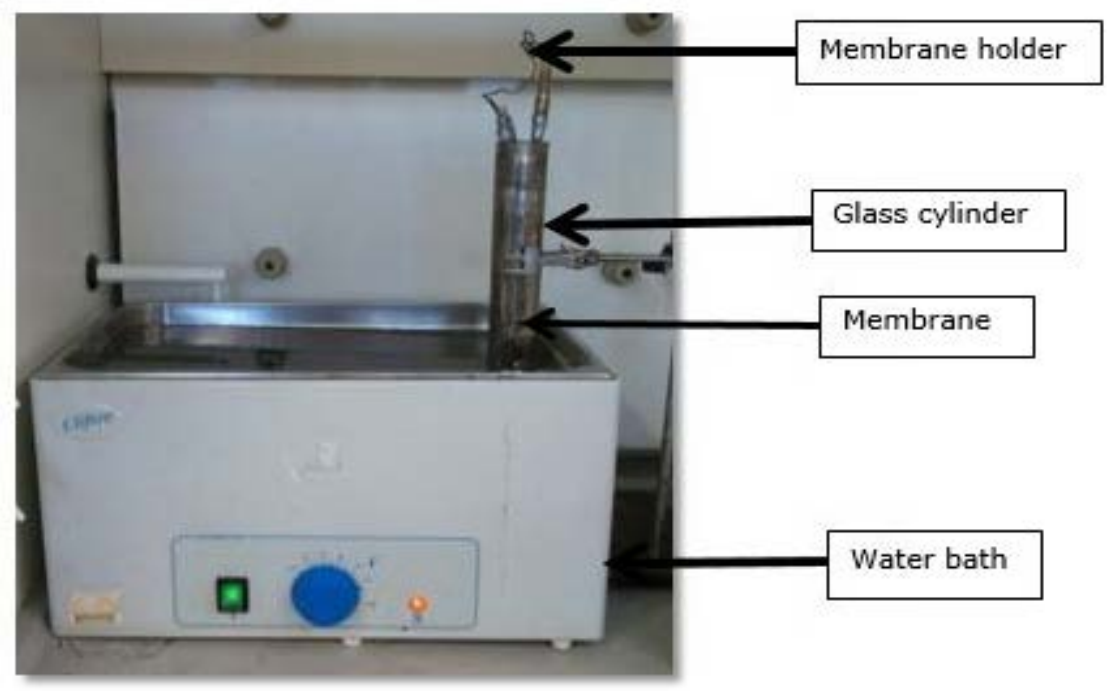

Fig. 1 Picture showing the electroless plating process of the palladium membrane

\subsection{Membrane characterization}

\subsubsection{Gas permeation}

Gas permeation experiments were conducted using the method adapted from Gobina (GOBINA, E. 2006). The schematic diagram of the experimental flow apparatus dedicated to the measurement of the gas permeation is shown in Fig 2. The apparatus, which is constructed by using standard UHV stainless steel components, is comprised of three main sections: feed gas delivery, membrane-holder and the permeate flow measurement. The membrane-holder consists of a stainless steel tube with threaded end-fittings at both ends to accommodate the 'O' ring high-temperature seals and threaded end-caps plugs which when screwed onto the steel tube threaded ends creates the seal that separates the shell-side from the tube-side and thus centralizes the membrane (6) to enable flow through the membrane from the shell-side into the tube-side. The outside surface of the stainless steel tube is wrapped in electric heating tape (RS Components) (5) and has three type K thermocouples (RS Components) (7) strategically located at the top, middle and bottom of the stainless steel shell to monitor and record the temperature. The pure gases from the high pressure cylinder (BOC, UK) (1) are fed through a gas inlet line that is constructed with copper pipes $(6 \mathrm{~mm}$ external diameter) to the shell-side of the membrane-holder (4) through a needle valve (2). The pressure in the gas inlet gas line during measurements is monitored using a digital pressure gauge (Keller LEO 2) (3) which is located between the needle valve (2) and the shell-side sample holder inlet. A digital flow meter (Cole parmer) (8) with full scale reading of $10 \mathrm{Litre}$ per minute $(\mathrm{L} / \mathrm{min}) \mathrm{H}_{2}$ and $0.01 \%$ full-scale (FS) resolution is positioned between the tube-side exit of the sample holder and the vent (9). With one of the tube-side inlets closed and one of the shell-side exits closed, the feed is directed to permeate into the bore of the membrane and in co-current flow into the flow meter where the flow rate is displayed and recorded. The experiments are repeated three times and an average value calculated.

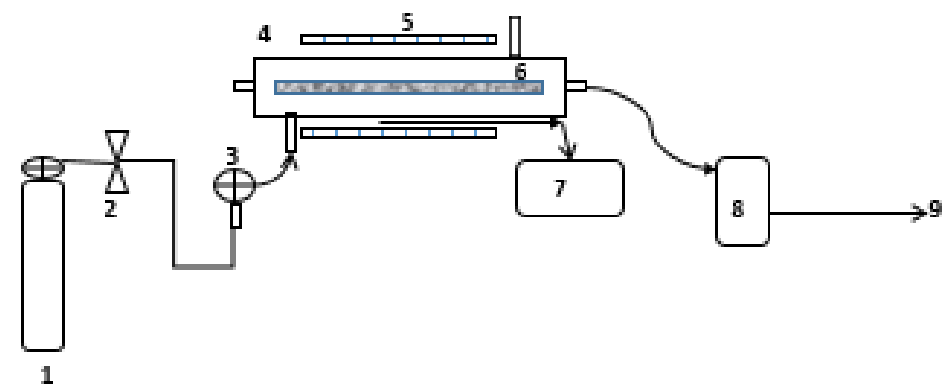

Fig 2 Schematic experimental diagram showing the membrane process for gas permeation analysis (1-Gas cylinder, 2Gas gauge control On/Off valve, 3-digital pressure gauge, 4-membrane holder, 5-heating tape, 6-membrane, 7thermocouple, 8-digital flow meter and 9-Vent 
The effects of transmembrane pressure drop of hydrogen, oxygen, helium and nitrogen gases across the membrane were investigated at $573 \mathrm{~K}$. The permeance was calculated from equation 1 (Carlos Finol 1999)

$$
J=\frac{F}{A \Delta P}
$$

Where $\boldsymbol{J}$ is the permeance $\left(\mathrm{mol} \cdot \mathrm{m}^{-2} \cdot \mathrm{s}^{-1} \cdot \mathrm{Pa}^{-1}\right), \boldsymbol{F}$ is the volumetric flow rate $\left(\mathrm{mol} . \mathrm{s}^{-1}\right) ; \boldsymbol{A}$ is the surface area of the membrane $\left(\mathrm{m}^{2}\right)$ and $\boldsymbol{\Delta P}$ the pressure drop across the membrane (Pa or bar). The selectivity across the membrane $\propto_{a / b}$ is given by the flux of gas a over that of gas $b$ and is denoted by equation 2 (Carlos Finol 1999) (Li and Liang 2012).

$$
\propto_{a / b}=\frac{J_{a}}{J b}=\frac{F_{a}}{F_{b}}
$$

Where $\propto_{a / b}$ is the permselectivity of gas a to gas $b, \boldsymbol{J}_{\boldsymbol{a}} \& \boldsymbol{J}_{\boldsymbol{b}}$ are the permeances and $\boldsymbol{F}_{\boldsymbol{a}}$ and $\boldsymbol{F}_{\boldsymbol{b}}$ are their respective flow rates through the membrane

The Knudsen selectivity of gas a over gas $b$ is given by the reciprocal of the square root of the ratio of their respective molecular weights as shown in equation 3.

$$
\propto_{\mathrm{a} / \mathbf{b} \text { (Knudsen) }}=\left(\boldsymbol{M}_{\boldsymbol{b}} / \boldsymbol{M}_{\mathbf{a}}\right)^{0.5}
$$

Where $\propto_{a / b}$ (Knudsen) is the Knudsen selectivity of gas a over gas $b, \boldsymbol{M a}_{\boldsymbol{a}}$ and $\boldsymbol{M}_{\boldsymbol{b}}$ are the molecular weights of gas a and gas $b$ respectively.

\subsubsection{Scanning electron microscopy (SEM)}

The morphological characterization of the palladium membrane was carried out using a Zeiss EVO LS10 Variable Pressure scanning electron microscope. The fragments of the palladium ceramic membranes were positioned on a stainless-steel disc "stub" using a suitable adhesive. This adhesive provides a firm grip of the sample to the stub as well as providing electrical continuity. The samples were loaded on the sample carousel while making sure that they are well positioned on a metal holder. They were then gold-coated using sputtering and operated under vacuum. The SEM photographs of the inner and outer areas were obtained at a number of different magnifications.

\subsubsection{Nitrogen adsorption desorption analysis}

The fresh support and palladium coated membrane were characterised using nitrogen adsorption-desorption (Quantachrome ${ }^{\circledR A S i Q w i n T M) ~ t e c h n i q u e ~ t o ~ d e t e r m i n e ~ a n d ~ c o m p a r e ~ t h e i r ~ p o r e ~ s t r u c t u r e s ~(Y e u n g, ~ S e b a s t i a n ~}$ and Varma 1997). The Brunauer, Emmett and Teller (BET) and Barrett, Joyner and Halenda (BJH) methods were employed to determine the specific surface area, average pore size and pore size distribution. This information was determined from the nitrogen adsorption and desorption isotherms at a liquid temperature of $77 \mathrm{~K}$. The process of nitrogen adsorption desorption comprised of two stages: degassing and analysis. Fragments of the catalytic membranes were ground into smaller pieces and $0.1 \mathrm{~g}$ of the sample was put into a cell which was degassed for about 5 hours at a temperature of $338 \mathrm{~K}$. The process of the degassing is done to remove any moisture or impurities that could be present in the sample. The degassed samples are then analysed at a temperature of $77 \mathrm{~K}$.

\section{RESULTS AND DISCUSSION}

\subsection{Gas permeation}

Three different gas transport mechanisms that are often involved in gas flow through supports can be distinguished, namely Knudsen diffusion, Molecular sieving and solution diffusion respectively. Also if the pores of the support are large enough then convective flow can occur but it does not involve any separation. Each of these transport process mechanisms can occur depending on the ratio of the molecular size of the flowing gas to the pore diameter of the support. When the pores of the support are relatively large $(0.1-10$ $\mu \mathrm{m}$ ) compared to the molecular size of gas molecules, then gases are transported by convective flow and therefore no separation occurs. If the pores are smaller than $0.1 \mu \mathrm{m}$, then the pore diameters is the same size as or lower than the mean-free-path of the gas molecules and such pores allow gas transport by Knudsen diffusion, whereby the flow rate of each gas is inversely proportional to the square root of its molecular weight and temperature. If the support pores are extremely small (i.e. order of $0.2-5 \mathrm{~nm}$ ), then the 
molecular sieving separation can occur. This is a relatively complex transport mechanism and can involve both gas phase diffusion and adsorbed species on the pore surface. However, as the mean-free-path (i.e. the ratio of the pore size to the size of the diffusing gas molecule decreases, the barrier becomes dense and transport occurs by a solution-diffusion mechanism, which involves the jumping of a bound molecule in one sorption site to another/other sorption sites with a specific frequency of vibration and jump length.

Fig. 3 illustrates the transport of the different gas through support used to prepare the palladium membranes at different pressure drops of gauge feed pressure (exit is at atmospheric pressure). It is clear from the nature of the plots that the diffusion is governed by Knudsen mechanism i.e. the higher the molecular weight, the lower the flow rate. At a given pressure drop it is observed that the permeation rate of hydrogen $($ molecular weight $=2)$ was $>$ helium $($ molecular weight $=4)>$ nitrogen $($ molecular weight $=28)>$ oxygen (molecular weight $=32$ ) and the selectivity for hydrogen to any of the gases investigated was inversely proportional to the square root of the ratio their molecular weights. Ideally, this should be equal to the ratio of their respective flow rates. For example, using the data of the permeation rates through the support presented in Table 2 at a pressure drop of 1.0 bar, we get that the ratio of the permeation rate of $\mathrm{H}_{2}$ to that of $\mathrm{O}_{2}$ is 3.685. This compares with the theoretical Knudsen value of 4.0 obtained by the square root of the inverse of the ratio of their respective molecular weights. Similarly, a value of 3.45 for the permeation rate ratio of $\mathrm{H}_{2} / \mathrm{N}_{2}$ compares with the theoretical Knudsen value of 3.742 and 1.956 compares to the theoretical Knudsen value of 1.41 for $\mathrm{H}_{2} / \mathrm{He}$.

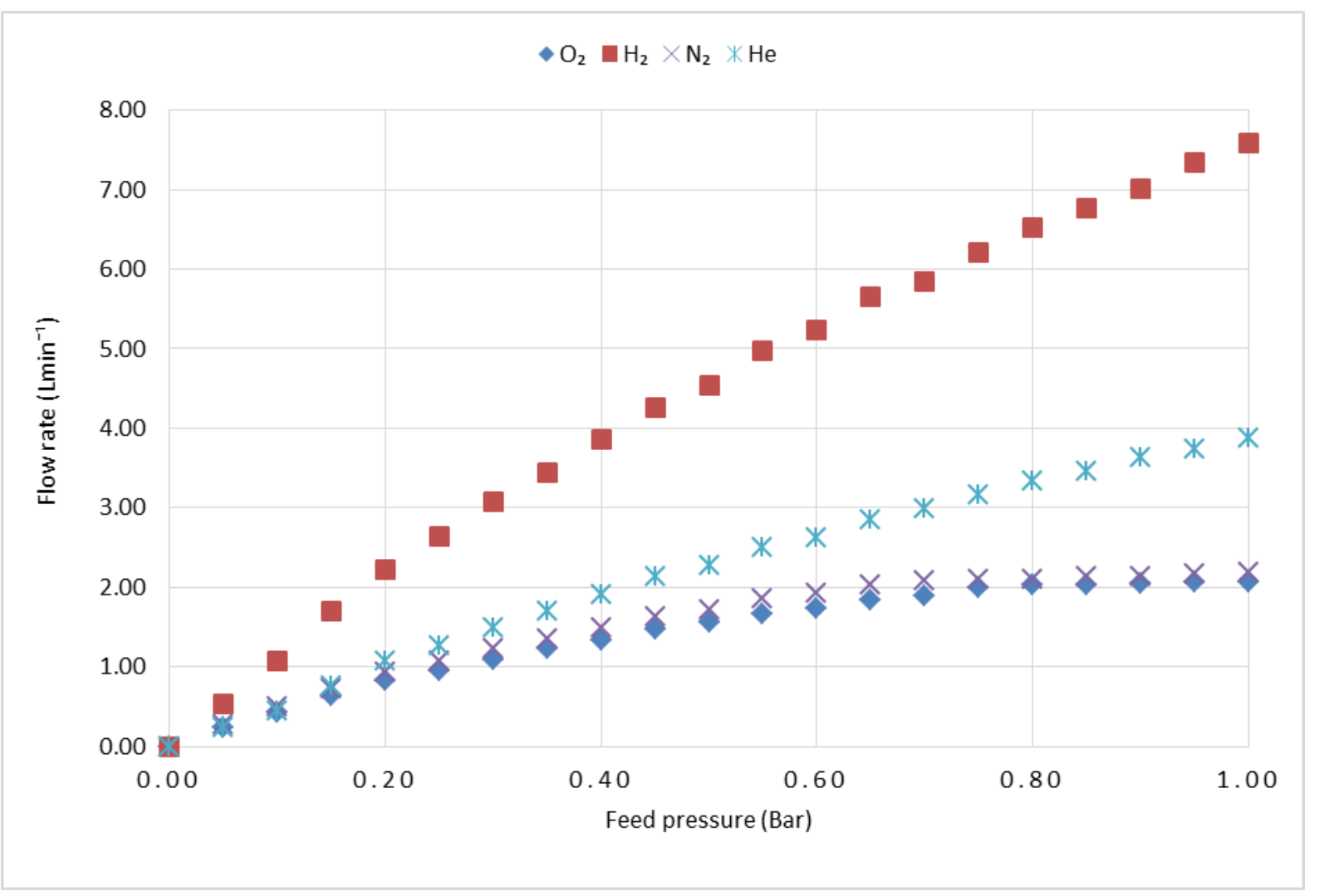

Fig 3 Graph of Flowrate (L/min) against gauge pressure for the support at $573 \mathrm{~K}$

Fig. 4a shows the plot of gas flow rate against the pressure drop across the membrane for $\mathrm{H}_{2}, \mathrm{~N}_{2}, \mathrm{O}_{2}$ and $\mathrm{He}$ for the $\mathrm{Pd} / \mathrm{Al}_{2} \mathrm{O}_{3}$ membrane. The gas transport follows a similar trend to that of Fig 3 , but the deployment of the palladium coating has reduced the permeation rate by almost $58 \%$ although $\mathrm{H}_{2}$ still showed a higher flow rate compared to other gases under the identical gauge pressure conditions. This result suggests that the palladium layer is not completely dense and exists as grains with grain boundaries that are porous. If this is the case then hydrogen and the other gas transports through the membrane by several mechanisms simultaneously. For hydrogen in particular the diffusion also includes solution diffusion through the dense palladium in addition to Knudsen, convective and molecular sieving mechanisms. If we carry a similar evaluation as we did in the case of the support, and using the $\mathrm{H}_{2}, \mathrm{~N}_{2}, \mathrm{O}_{2}$ and He permeation through the 
$\mathrm{Pd} / \mathrm{Al}_{2} \mathrm{O}_{3}$ membrane presented in Table 2 at a pressure drop of 1.0 bar we get that the ratio of the permeation rate of $\mathrm{H}_{2}$ to that of $\mathrm{O}_{2}$ is 3.09 which compares with the theoretical Knudsen value of 4.0 obtained by the square root of the inverse of the ratio of their respective molecular weights. Similarly, a value of 2.819 for the permeation rate ratio of $\mathrm{H}_{2} / \mathrm{N}_{2}$ compares with the theoretical Knudsen value of 3.742 and 1.944 compares to the theoretical Knudsen value of 1.41 for $\mathrm{H}_{2} / \mathrm{He}$.

The $\mathrm{H}_{2}$ having a significant difference in permeation from that of $\mathrm{N}_{2}$ was also reported by A. Li et al (Yeung, Christiansen and Varma 1999). The Knudsen flow and solution diffusion mechanisms were thought to be most predominant for $\mathrm{H}_{2}$ at this high temperature and the other gases showed a combination of Knudsen and viscous flow mechanisms. However, the $\mathrm{H}_{2} / \mathrm{He}$ permeation ratio was not significantly affected by the addition of the $\mathrm{Pd}$ layer. Helium is a small molecule and although having a molecular weight twice that of hydrogen, its kinetic diameter $\left(260 \times 10^{-10} \mathrm{~m}\right)$ is lower than that of hydrogen $\left(289 \times 10^{-10} \mathrm{~m}\right)$ and therefore while helium does not permeate through the dense portion of the palladium, it permeates faster through the porous grain boundaries than hydrogen due to its smaller kinetic diameter.

Fig. $4 \mathrm{~b}$ presents the permeance graph of the gases plotted against average pressure for the $\mathrm{Pd} / \mathrm{Al}_{2} \mathrm{O}_{3}$ membrane. It is noticed that they exhibit an initial viscous flow, and then as the pressure is increased further, a combination of several transport mechanisms occur, but the permeance of helium stay roughly constant. This confirms that the membranes were not completely dense and the other gases also permeated through the voids and cracks on the palladium layer.
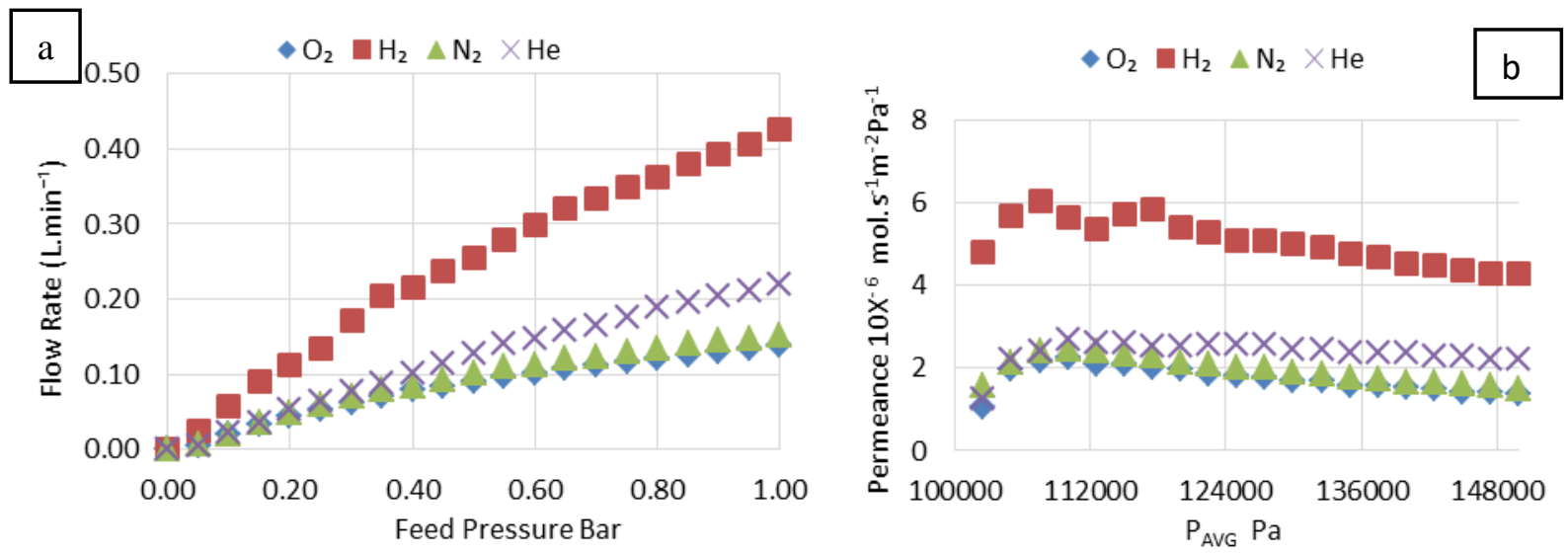

Fig 4 (a) Graph of Flowrate (L/min) against gauge pressure at 573 K, (b) Graph of Permeance against Average pressure

Fig. 5 presents a summary of the permeation data shown in Table 2. While high hydrogen selectivity is critically important in connection with purification and in catalytic membrane reactors used to increase the yield of thermodynamically limited reactions such as methane reforming and water-gas shift reactions by the effective and selective removal of the $\mathrm{H}_{2}$ produced from the reaction zone, it is not so important in situations in which the membrane has catalytic activity such that it is possible to carryout the reaction is such a fashion that the premixed reactants are forced-through the membrane on which the catalysts layer is attached in a single pass with the major aim of attaining complete reactants conversion which takes advantage of the very high catalytic efficiency that results from the intensification of contact between the catalyst and reactants. This type of catalytically active membrane has not been tested in gas-solid-liquid reactions and liquid-solid reactions before. With such a reactor configuration, it is possible to achieve good feed stream distribution and an optimal usage of the catalytic material and can thus out-perform those catalytic membranes in which the catalytic material is impregnated as highly dispersed particles in the pores of the support (Pina, Menendez and Santamaria 1996, Kajama, Nwogu and Gobina 2016). Work is underway at the Centre for Process Integration \& Membrane Technology in the Robert Gordon University, UK to deploy these $\mathrm{Pd}_{2} \mathrm{Al}_{2} \mathrm{O}_{3}$ membrane catalysts for the deoxygenating of water for downhole injection for pressure maintenance and in other process applications. 


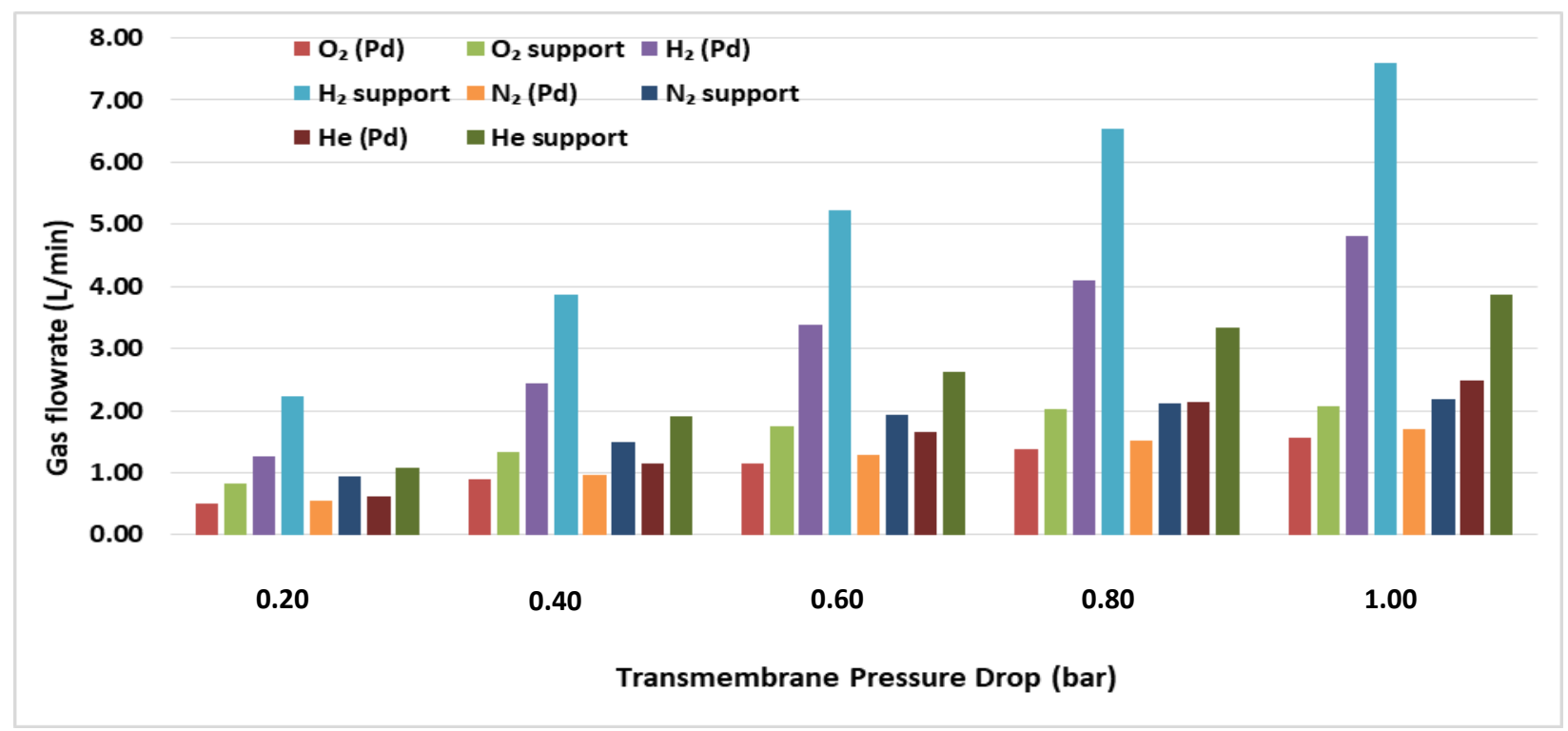

Fig 5 Comparison of gas transport characteristics through support and $\mathrm{Pd} / \mathrm{Al}_{2} \mathrm{O}_{3}$ membrane catalysts

Table 2 Measured flow rates of the various gases through the bare support and palladium-coated support

\begin{tabular}{|c|c|c|c|c|c|c|c|c|}
\hline Transmembrane & \multicolumn{8}{|c|}{ Gas Flowrate, L/min } \\
\hline $\begin{array}{l}\text { Pressure Drop } \\
\text { (bar) }\end{array}$ & $\mathbf{O}_{2}(\mathrm{Pd})$ & $\begin{array}{l}\mathbf{O}_{2} \\
\text { support }\end{array}$ & $\mathbf{H}_{2}(\mathrm{Pd})$ & $\begin{array}{l}\mathbf{H}_{2} \\
\text { support }\end{array}$ & $\mathbf{N}_{\mathbf{2}}(\mathrm{Pd})$ & $\begin{array}{l}\mathbf{N}_{2} \\
\text { support }\end{array}$ & $\begin{array}{l}\mathbf{H e} \\
(\mathrm{Pd})\end{array}$ & $\begin{array}{l}\text { He } \\
\text { support }\end{array}$ \\
\hline 0.20 & 0.51 & 0.83 & 1.27 & 2.23 & 0.55 & 0.94 & 0.61 & 1.08 \\
\hline 0.40 & 0.89 & 1.34 & 2.43 & 3.86 & 0.96 & 1.49 & 1.14 & 1.90 \\
\hline 0.60 & 1.15 & 1.74 & 3.38 & 5.23 & 1.28 & 1.92 & 1.66 & 2.63 \\
\hline 0.80 & 1.38 & 2.03 & 4.09 & 6.53 & 1.51 & 2.11 & 2.13 & 3.34 \\
\hline 1.00 & 1.56 & 2.06 & 4.82 & 7.59 & 1.71 & 2.20 & 2.48 & 3.88 \\
\hline
\end{tabular}

\subsection{SEM and EDXA Analysis}

Fig. 6a shows the Scanning Electron Microscopy (SEM) image of the surface of the palladium membrane, while the corresponding Energy Dispersive X-ray Analysis (EDXA) is presented in Fig. 6b. The surface showed a dense layer and this dense made consisting of different sized spherical clusters with voids around the edges. The manner in which the different shaped particles were packed creates these defects in the Pd coated layer. The thickness of the palladium film was also calculated and estimated to be $8.8 \mu \mathrm{m}$. The elemental composition of the $\mathrm{Pd} / \mathrm{Al}_{2} \mathrm{O}_{3}$ membrane shown in Fig. $6 \mathrm{~b}$ and is obtained from the EDXA spectra. The presence of the $\mathrm{Pd}$ can clearly be seen with very prominent peaks.

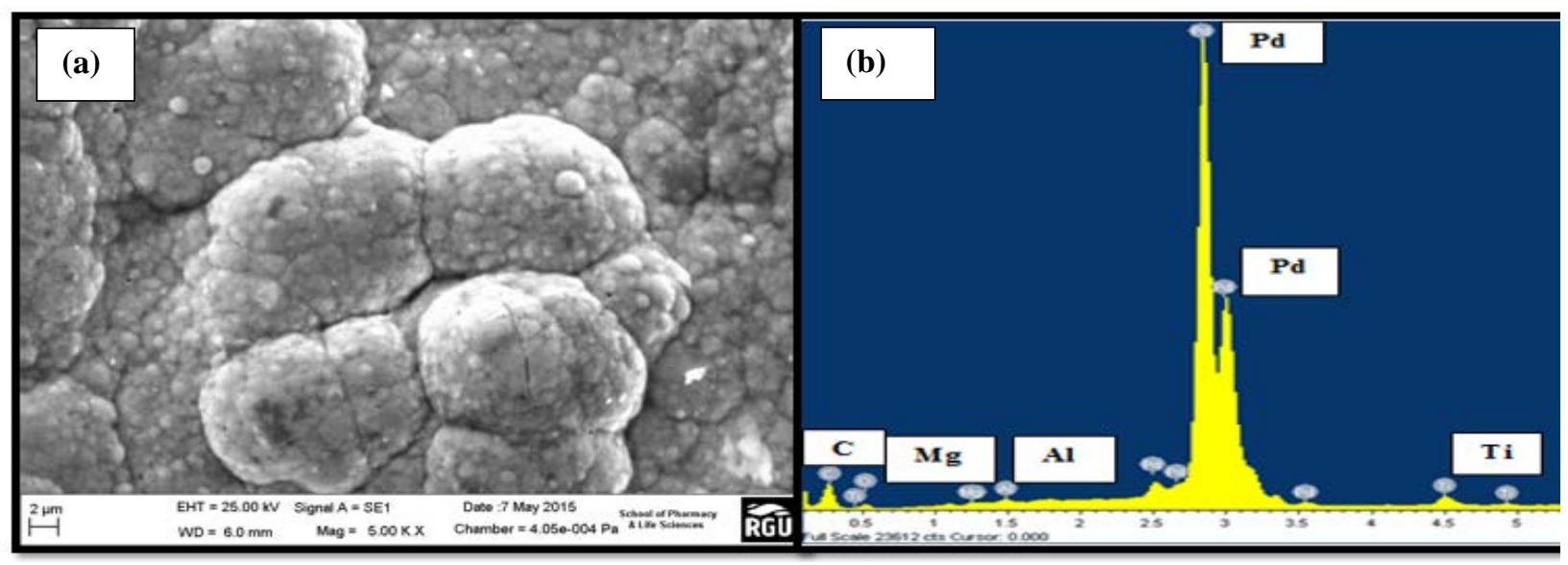

Fig. 6 Palladium coated membrane (a) SEM image of the outer surface (b) EDXA showing the elemental composition 


\subsection{Nitrogen adsorption desorption analysis}

The effects of palladium deposition on the structural features were also investigated. The physisorption isotherm obtained from the analysis of the palladium membrane is shown in Fig 7. The volume adsorbed was plotted against relative pressure $\mathrm{P} / \mathrm{Po}$, where $\mathrm{P}$ is the applied pressure and $\mathrm{Po}$ is the saturated pressure respectively. The isotherm obtained corresponds to the type IV isotherm as observed in Li (Li et al. 2014) and this shows characteristics of a mesoporous membrane undergoing capillary condensation.

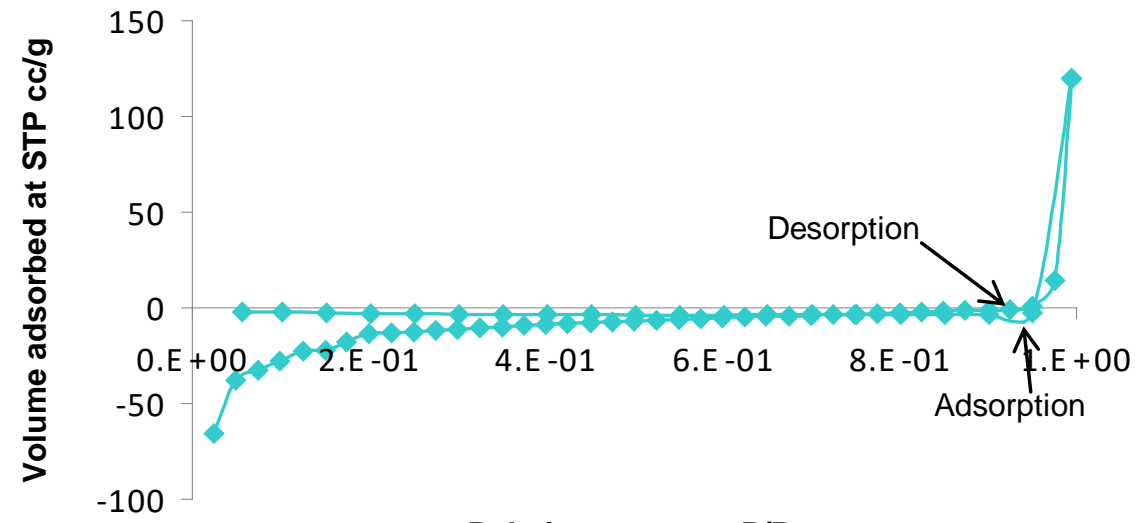

Relative pressure P/Po

Fig. 7 Physisorption isotherm of the palladium membrane

From the linear isotherm in Fig. 7, a nitrogen adsorption isotherm was generated using both the BrunauerEmmett-Teller (BET) and the Barrett, Joyner, and Halenda (BJH) methods. The specific surface area was then calculated from the graph and the summary of the results obtained from the BET analysis is shown in Table 3. It is observed that there was an increase in the surface area due to the effect of the palladium coating. The graph also calculated the pore diameter to be $3.305 \mathrm{~nm}$ with the help of the BJH analysis. Result summary is also presented in Table 3 and it is compared with that of a fresh support. It is observed that the pore diameter reduced from 3.305 to $2.973 \mathrm{~nm}$ with the effect of the palladium coating. This is a very good result because micropores are very important since they enhance the entrapment of the catalysts in the membrane and hence prevent the catalysts from being washed away by the water during the deoxygenating process. The nitrogen adsorption desorption shows a linear isotherm which corresponded to the characteristics of a mesoporous membrane. The increase in surface area and reduction of pore size of the membrane pores will further enhance the selectivity of hydrogen when compared to other gases.

Table 3 Results obtained from BET analysis of (a) palladium membrane and (b) fresh support

\begin{tabular}{|l|l|l|}
\hline Parameters & Fresh support & Palladium coated membrane \\
\hline Surface area $\mathrm{m}^{2} / \mathrm{g}$ & 0.247 & 9.660 \\
\hline Pore diameter $\mathrm{Dv}(\mathrm{d}), \mathrm{nm}$ & 3.305 & 2.973 \\
\hline
\end{tabular}

\section{CONCLUSIONS}

Gas transport behavior of a palladium composite membrane prepared by an electroless deposition technique has been evaluated at $573 \mathrm{~K}$. This type of catalytically active membrane is novel and has not been tested in gas-solid-liquid reactions and liquid-solid reactions before. The results showed hydrogen to have the highest flux over the range of pressure studied compared to other gases. The $\mathrm{Pd} / \gamma-\mathrm{Al}_{2} \mathrm{O}_{3}$ was characterized by SEM and nitrogen adsorption desorption methods. One of the characterization methods carried out was nitrogen adsorption. The results revealed that the membranes contained a significant level of micropores based on the pore size, pore size distribution and BET surface area. This is a very good result because micropores are an important artifact since they promote the entrapment of the membrane catalysts thus preventing the catalysts from being washed away by the water during the deoxygenation process. It is therefore both useful and advantageously necessary to confirm quantitatively what level of additional limitation in terms of flow and mechanistic aspects that the catalyst modified membranes have created by carrying out these single gas transportation experiments. The single gas transport study has therefore provided valuable and detailed additional information regarding the flow-through behavior of the novel catalytic membranes which the BET 
nitrogen adsorption equipment could not provide due to the fact that by its very nature nitrogen adsorption does not involve a flow-through process. Valuable information which could be used in understanding the novel catalytic membrane's performance can be deduced from the gas permeation results that have showed a significant increase in the catalytic membrane's surface area when compared to that of the fresh support. However there was a reduction in the average pore size in the novel catalytic membrane. The nitrogen adsorption desorption showed a linear isotherm which corresponded to the characteristics of a mesoporous membrane.

\section{ACKNOWLEDGEMENT}

The authors are grateful to the staff of Centre for Process Integration and Membrane Technology and School of Pharmacy and Life sciences, Robert Gordon University for their support in some of the result analysis. The financial support of the Climate Change and Management Corporation (CCEMC) now being operated by Emission Reduction Alberta (ERA), Grant number EO1\#K130073 is also greatly appreciated.

\section{NOMENCLATURE}

$\boldsymbol{A}=$ Surface area of the membrane $\left(\mathrm{m}^{2}\right)$

$\boldsymbol{F}=$ Flowrate $(\mathrm{mol} / \mathrm{s})$

$\boldsymbol{\Delta} \boldsymbol{P}=$ Pressure difference of gas across the membrane (Pa or bar)

$\boldsymbol{J}=$ Permeance $\left(\mathrm{mols}^{-1} \mathrm{~m}^{-2} \mathrm{~Pa}^{-1}\right)$

$\alpha_{a / b}=$ Flowrate of gas a divided by flowrate of gas $b(--)$

$\propto_{\mathrm{alb}}$ (Knudsen) $=$ Knudsen selectivity of gas a over gas $\mathrm{b}(--)$

$\boldsymbol{M}=$ Molecular weight of gas $(\mathrm{g} / \mathrm{mol})$

\section{REFERENCES}

Alique, D., Martinez-Diaz, D., Sanz, R. and Calles, J. A. 2018. Review of Supported Pd-Based Membranes Preparation by Electroless Plating for Ultra-Pure Hydrogen Production. Membranes, 8(5) pp 1-39

Carlos Finol, J.C., 1999. Permeation of gases in asymmetric ceramic membranes. Chemical Engineering Education, pp. 58-60

Chen, C.C. and Gobina, E. 2010. Ultra-thin palladium technologies enable future commercial deployment of PEM fuel cell systems. Membrane Technology, 2010(3), pp 6-13

Chen, C.C. and Gobina, E. 2013. Trial designs of ultra-thin palladium alloy membrane purifiers for highdensity hydrogen production Pt. 2. Membrane Technology, 2013(1), pp 7-10

Checchetto, R., Bazzanella, N., Patton B., and Miotello, A. 2004. Palladium membranes prepared by r.f. magnetron sputtering for hydrogen purification. Surface and Coatings Technology, 177-178, pp 73-79.

Collins, J.P. and Way, J.D., 1993. Preparation and characterization of a composite palladium-ceramic membrane. Industrial \& Engineering Chemistry Research, 32(12), pp. 3006-3013

Den Exter, M., 2014. The use of electroless plating as a deposition technology in the fabrication of palladium based membranes. Palladium Membrane Technology for Hydrogen Production, Carbon Capture and Other Applications, pp. 43-67

Fard, A. K., McKay, G., Buekenhoudt, A., Al Sulaiti, H., Motmans, F., Khraisheh, M. and Atieh, M. 2018. Inorganic Membranes: Preparation and Application for Water Treatment and Desalination. Materials, 11(74) pp 1-47

Gobina, E. 2006. Apparatus and method for separating gases. Washington, DC: US. Patent and Trademark Office $7,048,778$.

Hamilton, H, 2012. Palladium-based membranes for hydrogen separation. Platinum Metals Rev., 56, (2) pp. $117-123$

Jiang, K., Goldbach, A, Bao, C., Yu, C. and Xu, H., 2008. Performance of Large Pd/Ceramic Membranes during Separation of Reformate and $\mathrm{H}_{2} / \mathrm{N}_{2}$ Mixtures. Presented at the 10th International Conference on Inorganic Membranes, August 18-22, 2008, Tokyo, Japan. pp 1-2. 
Kajama, M.N., Nwogu, N.C. and Gobina, E. 2016. Catalytic membrane reactor for VOC destruction 1. S.-I. Ao et al. (eds). Transactions on Engineering Technologies, pp 163-177

Kikuchi, E. \& Uemiya, S. (1991). Preparation of supported thin palladium-silver alloy membranes and their characteristics for hydrogen separation. Gas separation \& Purification. 5, 4:261-266.

Kiliçarslan, S., Afyon, O.M. and Doğan, M., 2008. Preparation of Palladium Composite Membranes on Pore Structure Modified and Non-Modified Supports by Electroless Plating Procedure. Turkish Journal of Chemistry, 32(6), pp. 699-710

Li, K., 2007. Ceramic membranes for separation and reaction. ISBN: 9780470319475, John Wiley \& Sons, Ltd.

Li, A., Liang, W. and Hughes, R., 1998. Characterization and permeation of palladium/stainless steel composite membranes. Journal of Membrane Science, 149(2), pp. 259-268

Li, A., Liang, W. and Hughes, R., 2000. Fabrication of dense palladium composite membranes for hydrogen separation. Catalysis Today, 56(1-3), pp. 45-51

$\mathrm{Li}, \mathrm{H}$. et al., 2014. Experimental and modeling study of gas transport through composite ceramic membranes. Chemical Engineering Science, 108(0), pp. 94-102

$\mathrm{Li}, \mathrm{X}$. and Liang, B., 2012. Permeance of pure vapours in porous $\mathrm{Y}-\mathrm{Al}_{2} \mathrm{O}_{3} 3 / \alpha-\mathrm{Al}_{2} \mathrm{O}_{3}$ ceramic membrane. Journal of the Taiwan Institute of Chemical Engineers, 43(3), pp. 339-346

Pina, M.P., Menendez, M. and Santamaria, J. 1996. The Knudsen diffusion catalytic membrane reactor: an efficient contactor for the combustion of volatile organic compounds. Appl. Catal. B: Environ. 11, pp L19-27

Rahimpour, M. et al., 2017. Palladium membranes applications in reaction systems for hydrogen separation and purification: A review. Chemical Engineering and Processing: Process Intensification, 121, pp. 24-49

Yeung, K., Christiansen, S. and Varma, A., 1999. Palladium composite membranes by electroless plating technique: relationships between plating kinetics, film microstructure and membrane performance. Journal of Membrane Science, 159(1), pp. 107-122

Yeung, K., Sebastian, J. and Varma, A., 1997. Mesoporous alumina membranes: synthesis, characterization, thermal stability and non uniform distribution of catalyst. Journal of Membrane Science, 131(1), pp. 9-28 